\title{
Using the Adaptive Virtual Museum System for Mural Painting of the First Class Royal Temples
}

\author{
P. Jomsri
}

\begin{abstract}
Mural paintings is a strong part of Thai society and its heritage, along with its culture, traditions, and local wisdom. Mural paintings are not protected nor well publicized, with concerns that this kind of painting may become extinct. This study involved gathering and presenting mural paintings in the form of a virtual museum. The paintings were reproduced and developed into an online format to preserve the heritage of cultures and local wisdom as expressed in the mural painting of the First Class Royal Temples. This is a useful tool to encourage, and educate people about mural painting through the use of a virtual museum, in particular highlighting the difference in Thai mural paintings. Results indicate that users could easily improve their knowledge of mural paintings in the First Class Royal Temples through the virtual museum while at the same time efficiently educating and publicizing these mural paintings.
\end{abstract}

Index Terms-Virtual museum, mural painting, virtual reality, first class royal temples.

\section{INTRODUCTION}

Thai painting is considered an important part Thai cultural heritage and works of art since the pastime. Furthermore, this art was influenced from the beliefs and religion to explore the civilization of humanity. Thai painting in the pastime was related to Buddhism that reflected the life styles of people and events of history. As such, Thai painting is of high value as a historical record illustrating culture, beliefs, and religious faith, in particular detailing the architecture of Buddhism in Thailand. These paintings appeared on temple walls and other religious buildings as a way to provide a historical record. Those paintings are telling stories about history, Buddhism, and other events over time. Stories include the history of Buddha, tales, culture and Thai tradition in relation to Buddhism, which was highly respected by the Thai people. Thus, these paintings were cultural, historical, and Buddhist sources of learning for Thai people, and foreigners. Mural paintings in Thailand are scattered, making it difficult for people to see these works of art. What makes these paintings more valuable is that there are no other descriptions of Thai history and further, educate us on past Thai culture that differs to current Thai culture. While Thai mural paintings have been illustrated in books, conserving these works through online media makes them easily accessible for study by future generations.

Manuscript received June 20, 2017; revised November 20, 2017.

P. Jomsri is with Department of Information Technology, Faculty of Science and Technology, Suan Sunandha Rajabhat University, Bangkok, Thailand. (e-mail: Pijitra.jo@ssru.ac.th,pijitra_jom@hotmail.com).
The importance and problems mentioned above led to the construction of a virtual museum is a center of Mural Paintings observed in the First Class Royal Temples, and a form of publicizing the location of these paintings, their stories and meaning, and the knowledge retained through these paintings. This virtual museum used a computer program in presenting the paintings, and entertained users, as well as educated them about mural paintings, encouraging them to later visit the sites where the paintings are located. This system can motivate people to learn more about local paintings. A virtual museum was used as a model in gathering and presenting other Thai Mural Paintings in the future.

\section{RELATED WORK}

Virtual culture heritage Museum is a kind of presentation which is designed to draw a user's attention. With modern technology (i.e. the internet), it creates multimedia and mixed media in $3 \mathrm{D}$ with still pictures and motion pictures that can be viewed with an audio narrative. Users can also view a short clip, and feel as though they are at the location of the painting. The advantage of a virtual culture heritage museum are that users can get information before going to the location, saving time and enriching the experience. Users can also move the objects around to view them more closely. Many researchers develop a virtual system for public culture, travel and different forms of study. The prototype of virtual temple is a replica of the actual location developed for the website and allowing people who are interested in Rattanakosin Island to see it in a Panorama Pan View format [1]. In order to spread Thai folk wisdom on Thai style house building similar to the real thing, a researcher developed a web based Virtual Museum [2], [3]. A museum presentation about Thai architecture: case study Thai Lue houses were belted and studied the effectiveness of learning in virtual presentation. The study found that following the virtual media museum of Thai Lue houses, the understanding of students [4].

National Tainan Teachers College, Department of Earth Science studied the effect of using a virtual environment on student learning. Students were divided into two groups: the experimental group learned to create websites with VRML language and the first group learned from the virtual environment of the mountain city images in 3D. The second control group of students learned from normal method then measured their understanding of the difference of the scores on the test before and after learning (Pre-test \& Post-test). The results concluded that the use of virtual reality provided 
students with a better understanding than the students who studied through normal pictures. Thus, a free control system helps students to better learn and explore the environment [5].

Some researchers have created a system for the analysis and display of a collection of Native Californian baskets of Phoebe A. Hearst Museum of Anthropology. This research differs from existing cultural heritage applications in terms of the focus on tools and techniques to display objects, and to study the related ones. In the case of the basket, researchers developed a model in 3D, and exhibits in virtual view [6].

A guide for temples in Taipei for tourists was created. This research focuses on using Macromedia Flash program as a tool in creating parts of the tour in order to be used in Pocket PC. The user can interact with the map by the interactive panoramic images showing places where they want to see or where to go on the map immediately. Tourists can travel more easily and faster through information and images that appear in the panoramic virtual on Pocket PC [7].

The education content and site layout of Thai museum websites was studied. The samples are registered and unregistered websites with the names of "museums" in the sites, and there is a direct link to the page with the content of the museums for 28 sites in Thailand. The study found that, in terms of content, the content is mainly the history of the museum, and objects in museum, exhibition, and activities. The advertising section in the website did not focus on using multimedia both Thailand and English language together with links to other sites. In addition, they did not install chat rooms and online activities to entertain the audience [8]. The three-dimensional and three-dimensional animation has been applied widely in the study of science or learning of the true or real environment may require substantial costs. Hence, three dimensions will become really important in education [9]. Some researchers use local wisdom innovation in cultural heritage [10].

Any researchers were able to place the model in computer science using virtual panorama for Panoramic System Adjustment, gathering feedbacks from users, and assessing the data. This was later used to adjust and develop the website in order to maximize the efficiency, and minimize the errors. Model of the Department of Computer Science, FEE CTU. The purpose of the research was to create a model place of computer science using Quick Time VR: QTVR, where the audiences are feeling as they are at the location, and control their direction of movement, and view information about the property [11]. Another researcher studied the effect of using panoramic virtual slides in the study on the web for the academic achievement of students at Mattayom 4. The study found that students learned from field trips on the Web by using panoramic virtual media achieved better learning outcomes than students who studied with educational field trips on the Web by using a slide [12]. A preliminary development of virtual sight-seeing website for Thai temples on Rattanakosin Island was developed allowing people who are interested in Rattanakosin Island to see it in the form of Panorama Pan View.

A lot of research works have been proposed in the literature for digitalized protection and visualization of cultural heritage. While laser scanning, photogrammetry and computer vision approaches have been used extensively to record, measure, and preserve cultural heritage sites, they are only capable of displaying the current state of the environment with 3D models. This paper uses different views of Mural Painting of the First Class Royal Temples for public wisdom.

\section{Framework of Virtual Culture Heritage Museum SySTEM FOR MURAL PAINTING OF THE FIRST ClASS ROYAL TEMPLES}

In developing a virtual culture heritage museum system, to expose Thai people and foreigners to Thai local wisdom, as well as provide information that can serve in planning travel. There are 7 steps in development is as follows (also see Fig. 1):

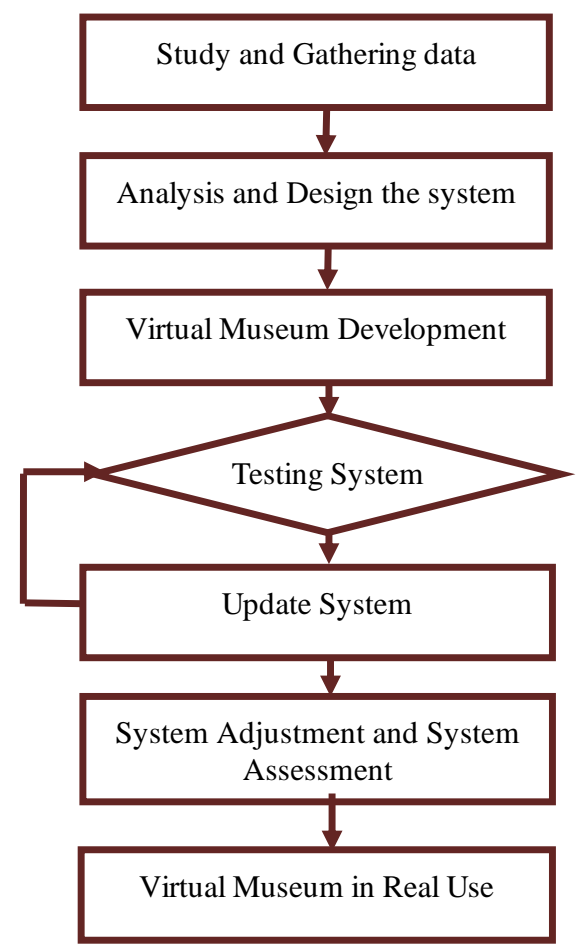

Fig. 1. A framework for preliminary development of virtual museum.

1). Study and gathering is a researcher studied and gathered data, differences, and took photos from the real sites both in text, visual, and audio covering Mural Painting of the First Class Royal Temples in Thailand. The scopes of this research area are in Bangkok and with 14 temples.

2). Analysis and design system is through analysis of systems and web design, the web structure was designed according to the information technology to present the details in Mural Painting of the First Class Royal Temples in Thailand such as pillars, gables, and construction regarding regions and living styles.

3). Virtual museum development is process for researcher developed Virtual Museum based on analysis and system design.

4). Testing system is tested regarding analysis and systems designs by experts.

5). System adjustment is gathered via feedback from users, 
and assessment of data. This was utilized to refine the website to maximize efficiency, and minimize errors.

6). System assessment is to assess the Virtual Museum, the samples of users were selected through questionnaires. Then, the data brought to analyze the hypothesis.

7). Virtual museum in this process is to bring the system into the real use through network.

\section{DeVElopment And Evaluation System}

To develop the system, a researcher took pictures from important parts of Mural Painting of the First Class Royal Temples in Thailand, used Visual C\#, Adobe, and Fig. 2 to Fig 4 show an example of development process. To assess the systems, a researcher asked 50 system experts including students and other people to volunteer in assessment. The subjects were asked to rate the relevancy of the search results on a five-point scale:

Score 1 is the level of satisfaction improvement

Score 2 is minimum level of satisfaction

Score 3 is medium level of satisfaction

Score 4 is good

Score 5 is very good satisfaction

Moreover, a T-test was used in analyzing the data before and after using the systems.

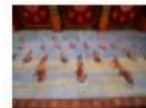

IMG 6908.jpg

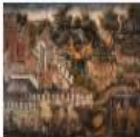

IMG_6940.jpg

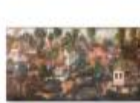

IMG_6958-2.jpg

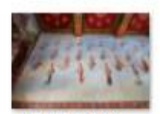

IMG_6909.jpg

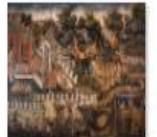

IMG_6940-2.jpg

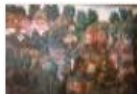

IMG 6961.jpg

IMG_6961-2.jpg

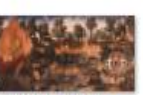

IMG 6948.jpg

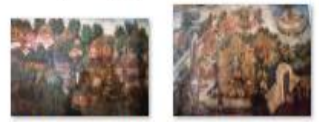

IMG_6965.jpg Fig. 2. Example of first step for gathering data.

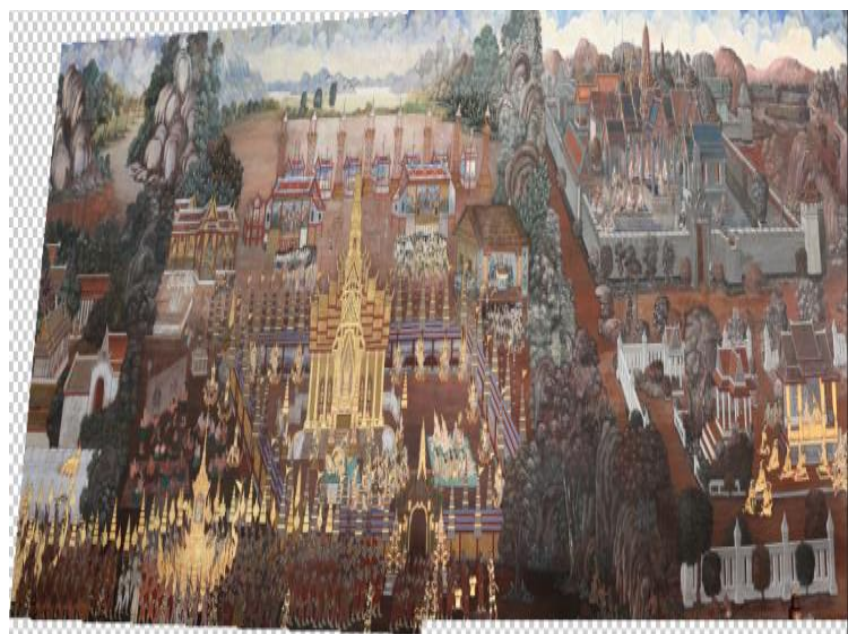

Fig. 3. Example of third step for development process.

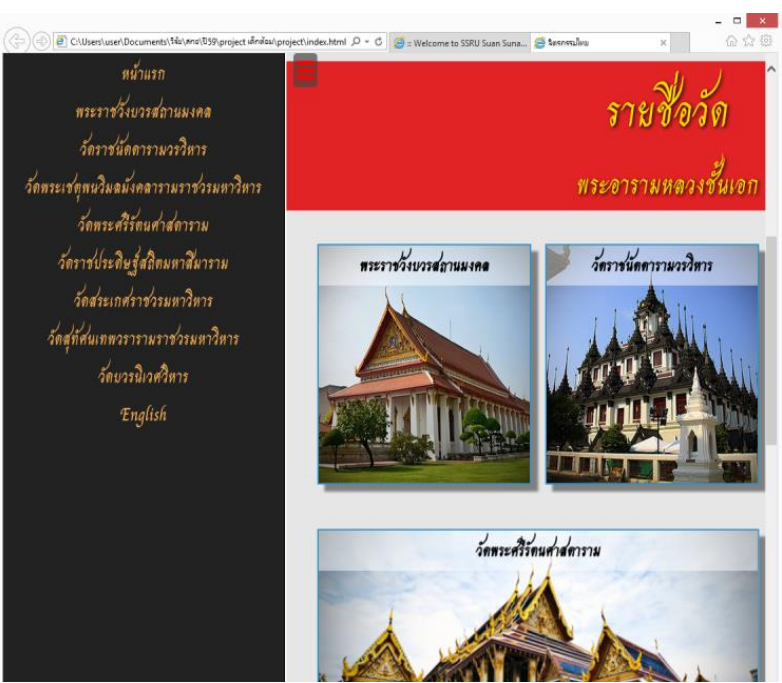

Fig.4. Example of interface for mural painting of the first class royal temples.

\section{RESUlt AND DisCUSSION}

The result from the assessment in satisfaction in Virtual Museum of Mural Painting of the First Class Royal Temples showed that system reliability and information was 4.29 and reliability was 0.35 which was a good result as shown in following tables:

TABLE I: THE RESULT OF THE ASSESSMENT

\begin{tabular}{|c|c|c|c|}
\hline $\begin{array}{l}\text { An example of a column } \\
\text { heading }\end{array}$ & $\begin{array}{l}\text { Overall } \\
\text { Average }\end{array}$ & Reliability & Criteria \\
\hline $\begin{array}{l}\text { Learn more about mural } \\
\text { painting }\end{array}$ & 4.55 & 0.22 & Very good \\
\hline Design and Structure & 4.21 & 0.32 & Good \\
\hline Fonts & 3.97 & 0.42 & Good \\
\hline Colors & 4.25 & 0.47 & Good \\
\hline Pictures and multimedia & 4.2 & 0.25 & Good \\
\hline Designs are suitable to users & 4.58 & 0.42 & Very good \\
\hline Total & 4.29 & 0.35 & Good \\
\hline
\end{tabular}

The mean difference was applied for assumption that the knowledge of the user about mural painting between before (MTBModel) and after (MTAModel) use virtual museum system difference, a paired-sample T test is employed. It was assumed that the sample comes from populations that are approximately normal with equal variances. Level of significance is set to $0.05(\alpha=0.05)$. The results can be summarized as follows:

TABLE II: PAIRED-SAMPLE T-TEST

\begin{tabular}{clccc}
\hline \hline \multirow{2}{*}{ Pair } & \multicolumn{5}{c}{ Pair differences } \\
& $\begin{array}{l}\text { Std. } \\
\text { Deviation }\end{array}$ & $\begin{array}{l}\text { Std.error } \\
\text { Mean }\end{array}$ & Sig & Mean \\
& .752 & .258 & .422 & .001 \\
\hline MTBModel-MTAModel & .425 & & \\
\hline
\end{tabular}

Statistical testing result from Table II indicates that there is a significant difference in the confidence values of the MTBModel and MTAModel at $\alpha=0.05$. In other words, the mean scores of confidence values of MTBModel and MTAModel are not the same. 


\section{CONCLUSION AND FUTURE WORK}

The study developed a virtual museum on Thai Mural Paintings by studying various related systems, and created a virtual museum. The objective was to publicize knowledge of local wisdom on Thai Mural Painting of the First Class Royal Temples. The results indicate that the system could improve users' knowledge to a good standard. Further the virtual museum was suited to users of any age. Content was according to the needs of user, being continuous and efficient.

This virtual museum covered only the First Class Royal Temples. Other locations can be developed for use on use on a social network.

\section{ACKNOWLEDGMENT}

The authors would like to thank Suan Sunandha Rajabhat University for scholarship support.

\section{REFERENCES}

[1] P. Jomsri, "A preliminary development of virtual sightseeing website for Thai temples on Rattanakosin Island," International Journal of Social, Management, Economics and Business Engineering, vol. 7, no. 12. 2013.

[2] P. Jomsri, "The development of virtual museum for Thai style houses in four regions," International Journal of Information and Education Technology, vol. 6, pp. 410-413, 2016.

[3] S. Nuanmeesri, P. Kadmateekarun, and L. Poomhiran, The Development of Augment Realization for Thai Phra Ratcha Niyom, 2015.

[4] G. Khainaga, "The creation of virtual museum for promoting education in Thai architecture: A case study of Thai lue house," Master thesis Chiangmai University, 2008.
[5] L. Fung-Chun, J. Angelier, B. Deffontaines, H. Jyr-Ching, H. Shih-Hao, C. Lee, C. Huang, and C. A Chen, "Virtual reality application for distance learning of Taiwan stream erosion in geoscience," ICCE 2002, pp. 1156-1160, 2002.

[6] V. Isler, B. Wilson, and R. Bajcsy. (2006). Building a 3D virtual Museum of native American baskets. [Online]. Available: http://www-users.cs.umn.edu/ isler/pub/3dpvt06.pdf

[7] C. Y. Tai, "Temple of Taipai a handheld tour guide for pocket PC," Department of Telecommunication, Michigan state University, 2003.

[8] W. Poompaga, "Educational content and layout of the site in Thailand Museum," Master thesis, Mahidol University, 2001.

[9] T. Hagward, Adventure in Virtual Reality, Indianapolis: Que Corporation, 1993.

[10] J. Boonpracha, Local Wisdom Innovation in Cultural Heritage of Applying Relation between Colors of Five Element and Colors of Benjarong to Develop Souvenir Product of Communities, Office of the Higher Education Commission, 2011.

[11] D. Pavlicek. Panoramic Model of the Department of Computer Science. FEE CTU. [Online] Available: http://www.cgg.cvut.cz/publication/diplom/PavlicekDusan/abstract_ht $\mathrm{m}$

[12] N. Yodsin, "Effects of virtual panorama image in educational field trips on web upon learning achievement of mathayom suksa four students,' thesis, Chulalongkorn University, 2004

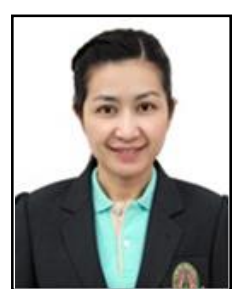

P. Jomsri was born in Thailand in 1981. She received her B.Sc in statistic from Thammasat University, and M.S. in computer science from Slipakorn University. She received her doctorate degree from Chulalongkorn University in 2013 in the field of computer science and information technology. She is a lecturer in major information technology at Suan Sunandha Rajabhat University. Her research work is in the areas of virtual system, information retrieval, web technology and network system. 
Image Processing and Application 
